\title{
Manuel Gutiérrez Estévez, Imágenes y sentimientos en el cristianismo popular. Viejos testimonios de fieles extremeños, (Madrid, CSIC, 2016), 697 pp.
}

La benemérita colección De Acá y de allá: fuentes etnográficas, que creó e impulsó Luis Díaz Viana (quien sigue siendo uno de sus pilares) y que hoy dirige Luisa Abad en el CSIC, lleva publicados, con este, quince volúmenes que están contribuyendo a que la etnografía española (con unas cuantas incursiones en la de Hispanoamérica) esté cobrando el perfil propio y singular que le han estado y que le siguen disputando o cicateando, desde hace mucho, disciplinas mejor posicionadas en las instituciones académicas, como son la antropología, la sociología, la ciencia de las religiones, e incluso la historia y la filología.

La reivindicación y dignificación de la etnografía como ciencia con objetivos y métodos propios, y no solo como disciplina auxiliar de otras, es una tarea que no solo puede contribuir a que adquiramos una percepción más completa y fidedigna de las culturas que dan sustento a las aparatosas hermenéuticas que se encargan de construir los pensadores sociales; puede también ayudar a que todas esas ciencias sociales canónicas o canonizadas mejoren y se regeneren de arriba a abajo, en tanto que perfeccionar los cimientos puede ser esenciar para la consolidación y la salud de todo el edificio.

Manuel Gutiérrez Estévez reconoce, en los prolegómenos de su libro, la influencia que acusa de las teorías y objetivos de Durkheim o de Lévi-Strauss (en particular del segundo, y de sus teorías acerca de "la mente salvaje"), pero asume una metodología absolutamente opuesta a la de ellos y a la de quienes se sienten más antropólogos que etnógrafos. Durkheim y Lévi-Strauss son ejemplos de pensadores que construyeron sus sociologías y antropologías a costa de sus etnografías: resumiendo, mutilando y manipulando, destacando algunas partes y silenciando otras, según conviniera, de los discursos e informes en que se basaron. El libro que ahora tenemos entre las manos ofrece justamente lo contrario: transcripciones literales, sin trampas ni cartones, de los discursos que, en 1983 y 1984, fueron registrados a los narradores, mujeres y hombres, de los diecinueve pueblos extremeños que fueron encuestados por un equipo que dirigió el autor y en el que participaron, haciendo labores de campo y de gabinete, los entonces jóvenes licenciados Ana Belén Casado, Maricer González Enríquez, Pedro Pitarch y Ana Erice. El proyecto fue auspiciado y financiado por el Centro de Investigaciones Sociológicas (CIS).

Las intervenciones mayores que el etnógrafo se ha permitido han sido, al margen de la labor implícita pero trascendental, por supuesto, de diseñar en la teoría y de llevar a la práctica todo el proyecto, las de reproducir un escueto pero sustancioso "informe sobre devociones populares en Extremadura (1984)" que Gutiérrez Estévez redactó al completar y entregar, hace más de treinta años, los frutos de su trabajo a la institución patrocinadora; añadir una "introducción" y una "nota final (o epílogo)", aún más escuetas, firmadas en 2016, en que hace una evaluación objetiva y reflexiva de aquellos trabajos de entonces; sumar un prólogo comprensivo y argumentado de Luis Díaz Viana 
que desentraña claves del trabajo y las claves de lo que puede aportar al panorama de las ciencias humanas de hoy; y seleccionar, en fin, entre el océano de testimonios que él y su equipo registraron en 1983 y 1984, aquellos que se ajustaban de manera específica a los objetivos y titulares concretos de este libro ("Imágenes y sentimientos en el cristianismo popular. Viejos testimonios de fieles extremeños"), dejando para otras ocasiones y publicaciones los que miraban más hacia otras realidades y materias. El autor anuncia, por ejemplo, que Ana Erice y Jorge de Persia "estuvieron preparando un interesante apéndice de literatura oral extremeña sobre santos, vírgenes y cristos, algo que quizá merezca la pena publicar en otra ocasión”. Ojalá esa parcela de aquellos trabajos, que tan prometedora suena y que intuimos que será más que un mero "apéndice", esté pronto al alcance de todos.

Los resultados que han quedado encerrados en este (¿primer?) libro acerca de la religiosidad popular extremeña acometido por Gutiérrez Estévez son una magna celebración, con resultados importantísimos, de la etnografía como ciencia con contornos propios y con formas de organización diferenciadas de los de las ciencias aledañas. Tan diferenciadas que los materiales transcritos de manera literal se agrupan en torno a cuatro ejes temáticos absolutamente nítidos y explícitos, y no conforme a los grandes e intelectualizados ciclos hermenéuticos y a los símbolos arduos que suelen preferir antropólogos y sociólogos como pautas para sus guiones: "Comentarios sobre diversos asuntos religiosos", "Testimonios devocionales acerca de Dios y de Jesús", "Testimonios devocionales acerca de la Virgen", y "Testimonios devocionales acerca de los santos". Más sencillo, imposible.

La primera categoría engloba las respuestas que se pronunciaron "sobre diferencias generacionales", "el cambio de las costumbres", "la fe y la práctica", "la devoción personal", "la confesión y la comunión", "los rezos", las "promesas y sacrificios" y "la Iglesia y los curas". La segunda recoge opiniones e interpretaciones acerca de "Dios Padre", el "Espíritu Santo", "Jesucristo", "Cristo Resucitado", la "Santa Cruz", el "Corpus Christi", el "Sagrado Corazón de Jesús", el "Nazareno", el "Santo Entierro"; el "Niño Jesús", el "Niño Jesús de Praga", el "Cristo Amarrado a la Columna", el "Cristo de la Humildad y la Paciencia", el "Cristo de la Misericordia" y nueve advocaciones más de Cristos diversos. La categoría tercera engloba los testimonios y creencias acerca de la "Virgen María en general", la "Virgen Candelaria", la "Virgen de Aguas Santas", la "Virgen de Altagracia", la "Virgen de Argeme", la "Virgen de Belén", la "Virgen de Carrión" y otras veinticuatro advocaciones marianas adicionales. Y la cuarta sección atiende a los "santos en general", "san Agustín", "san Antonio Abad", "san Antonio de Padua", "san Bartolomé" y otras veintiocho figuras más de santos. La resistencia del libro y de su autor a plegarse a las ordenaciones a menudo sofisticadas y tortuosas, proclives casi a lo ensayístico, de la antropología y de la sociología convencionales, queda absolutamente de manifiesto. El hecho, en fin, de que los informes acerca de los santos sigan el orden del alfabeto, y no se acojan a las alternativas que hubiera sido posible proponer, sobre el eje de los ciclos del calendario o de las afinidades temáticas, por ejemplo, reflejan la intención de proponer una etnografía pura y escueta, lo más alejada posible (aunque no blindada totalmente, lo cual sería imposible) de contaminaciones y vicios ideológicos y hermenéuticos.

Advierte Gutiérrez Estévez, a modo de tarjeta de presentación y de declaración de objetivos que, "a diferencia de lo que ha sido habitual en los estudios sobre religión, este libro no está centrado en el estudio del ritual, del culto público, sino en la devoción privada con su cortejo de emociones tácitas, no verbalizadas nunca totalmente. Los 
testimonios de los fieles extremeños de comienzos de los años ochenta son discursos personales - a veces parecen incluso confesiones-, que están impregnados de afectividad, desbordados por ella. Ya hablen de los favores recibidos de san Antonio o de la conducta incorrecta de los curas de la época, la continuidad entre el sentir, el pensar y el actuar se manifiesta por doquier en las palabras de los devotos. Y en este sentido, el libro puede ser visto como un fruto del giro afectivo (como se dice, por analogía con el giro lingüístico) que han experimentado las ciencias sociales en los últimos años. Lo afectivo no es algo añadido a lo social, no es un ingrediente más, sino que se confunde con ello (como sucede en todos estos textos). Las tentaciones que pudieran tenerse para, apoyándose en ellos, generar argumentos sistemáticos y totalizadores o formalizaciones geométricas son de imposible cumplimiento. Su realidad caleidoscópica, siempre móvil, convierte en inútiles los esfuerzos analíticos convencionales".

En mi opinión, esta monografía acerca de las Imágenes y sentimientos en el cristianismo popular. Viejos testimonios de fieles extremeños va mucho más allá de reflejar el giro afectivo, es decir, el repertorio de las creencias y las emociones de las personas cuyas opiniones y juicios fueron registrados. Es testimonio también del giro lingüistico y del giro literario, y hasta podría decirse que del giro historiográfico (tal y como indican las historias orales y las historias de vida, cuyo cultivo conoce hoy una enorme expansión), hacia el que las ciencias humanas van, según se advierte cada vez más, orientándose; eso si entendemos todas esas nociones como formas de reconocimiento del valor que la voz individual, las creencias personales y la biografía de cada sujeto pueden tener como construcciones de discurso lingüístico y de expresión literaria, además de como indicios de una historia general que puede y debe ser construida, también, a partir de la suma de las historias individuales.

Tampoco son ajenas, estas páginas, a lo que podríamos llamar giro visual que también está imantando, cada día más, los focos de nuestras ciencias humanas. El libro lleva insertas ciento sesenta fotografías que fueron realizadas, la gran mayoría de ellas, en los años 1983 y 1984, en el marco en que se desarrolló el trabajo de campo, y que forman una unidad inextricable con los testimonios verbales hermanos. De hecho, para los campesinos extremeños cuyas voces quedaron transcritas en estas páginas, las imágenes de tal Cristo, Virgen o santo no eran complementos o ilustraciones al margen, ni mucho menos, sino centros alrededor de los cuales giraban todo el sistema de creencias y de ritos de los que hablaban en las entrevistas.

Para los filólogos y para los estudiosos españoles de la literatura oral (permítanseme el excurso y la autocrítica), estas Imágenes y sentimientos en el cristianismo popular. Viejos testimonios de fieles extremeños han de ser un acicate para reflexionar acerca de las torpes y dogmáticas clasificaciones en que solemos embutir los repertorios narrativos (los testimonios, como los etiqueta hábil y diplomáticamente el título de este libro) que caen en nuestras manos. "Cuentos" y "leyendas" son las clasificaciones más socorridas. "Caso" es una categoría precisa y significativa pero que casi nunca es empleada por los filólogos, cuando muchas de las unidades de discurso que contiene este libro cabrían en ella mejor que en ninguna otra. "Noticia", "recuerdo", "creencia", "juicio", "opinión", "conjetura" y unas cuantas más que tampoco se utilizan casi nunca dentro de paradigmas críticos estructurados podrían y deberían tener una presencia relevante dentro de ese cuadro que debiera estar mucho mejor definido y rodado. El sinnúmero, la cantidad, la variedad, la naturalidad y la espontaneidad de los relatos que contiene esta monografía dan como saldo una colección riquísima de 
testimonios asociables a todas esas categorías y, seguramente, a algunas más. Son, pues, una invitación a que, entre todos, pensemos y definamos una clasificación de los repertorios del discurso oral (al margen de que pueda ser puesto subsidiariamente por escrito) que huya de simplificaciones y prejuicios y reconozca la pluralidad de los puntos de vista, las emociones, los niveles de asimilación, convencimiento o duda, en lo que puedan tener de conformadores no solo de los relatos individuales, sino también de la poética propia de cada grupo de relatos.

Es imposible dar cuenta, en una reseña breve (sería igual de imposible si fuera larga), de la cantidad, calidad, significados y proyecciones de los testimonios que han quedado transcritos en este libro. Antropología, sociología, ciencia de las religiones, historia (e historia de las mentalidades, de las ideas, de la vida cotidiana, de la mujer y del varón, etc.), fílología, dialectología, psicología incluso, encontrarán aquí minas de material casi inagotables. Intentemos evaluar, por ejemplo, sobre cuántas cuestiones (en especial de historia y de sociología) informa este testimonio:

En el año cuarenta y cinco hubo concentración de vírgenes en Cáceres. Acudieron casi todas las patronas, pero la única que llevaba melena peiná era esta (la de Altagracia) [del pueblo de Garrovillas]. Bueno, cuando llegó a la Cruz de los Caídos. ¡Madre Santa la que se lio allí!, discutiendo con los casareños que son también unos fanáticos... Me acuerdo que estábamos unas cuantas juntas: la mía es mujer, pero la tuya es muñeca; tiene cara de muñeca.

Asomémonos ahora a esta confesión, que interesará sobre todo a antropólogos y psicólogos, que hizo "Doña J. P., de 50 años, en Plasencia (Cáceres), 1984". Un relato, en primera persona, de valor inconmensurable, que nos introduce casi en el corazón de lo que don Julio Caro Baroja hubiera denominado "una vida mágica" y nos acerca a la percepción que de sus propias capacidades carismáticas puede tener un sujeto social y cultural en quien se encarnan creencias y atributos que se relacionaron, en siglos pasados, con sanadores místicos y muy en especial con saludadores, que eran unos curanderos especializados en el tratamiento de la rabia, de los que solía decirse, entre otras cosas, que lloraban en el vientre de su madre:

Por eso digo, si yo tendré algo con Dios bendito. Yo presiento lo que me va a pasar, pero mi familia no me lo cree.

Cuando me voy a poner un disgusto muy grande, muy grande, me veo muchas serpientes alrededor, muy viejas y muy gordas, y otras muy chiquininas. Y después de un momento a otro, han desaparecido. Eso, o toros. Cuando me sueño con toros, o con esas bichas, al día siguiente tengo un disgusto terrible. Y si hay algo malo, un accidente o alguna cosa, yo tengo un presentimiento de lo que me va a pasar.

Llevo muchos días con ganas de llorar, muy triste. Sin saber lo que yo tengo, pero con ganas de llorar. A mí me presiente lo que va a pasar. Por eso digo si Dios bendito tendrá alguna cosa conmigo.

- Con los toros sueño que vienen detrás de mí y me tiran al pozo del agua y me sacan y me tiran otra vez para arriba.

Cuando tengo una bronca o un disgusto. Y eso digo, si no será alguna brujería. Porque si no de qué. $\mathrm{O}$ es que yo en el vientre de mi madre, me dijo que me había sentido llorar. Yo sé que a mí los perros no me muerden, me ladran. Y los perros rabiosos tampoco. Porque estando en Moraleja, un perro de majada, que estaba rabioso, nosotros teníamos mucha costumbre de bajarnos a dormir debajo de los árboles, y yo estaba dormida. 
Yo me dormí mi siesta y cuando me despertaba, tenía el animal al lado. Y detrás han venido unos pastores a decirnos que tuviéramos cuidado. Y estaba dormido al lado. Por eso digo que yo tengo alguna cosa ante Dios o que me han embrujado; alguien sin querer, que tenga esa facilidad.

_ ¿Por qué tengo yo que pensar en brujas?, ¡si yo no he hecho mal a nadie! Yo creo más que sean cosas que yo tengo con Dios bendito. Que él me tenga al ver mis sentimientos, que me esté él observando. No sé si no será un Juicio Pascual ante Dios. Yo vengo pensando esto desde que él se me apareció, porque es que me despertaba el resplandor de él. Y aun todavía le he cogido más cariño y más fe, porque él ha venido cuando yo estaba muy apenada.

Asomémonos ahora al relato que se le vino a la cabeza, cuando fue preguntada sobre lo que creía acerca de "dios Padre", “doña J. L., de 75 años, en La Codosera (Badajoz), 1984”:

-Eso es como un cuento de Dios y el diablo, cuando Dios sembró una senara junta con el diablo. Dios sembró una senara, una sementera, junta con el diablo. Tenía una huerta, tenía una huerta, y dijo el diablo pa nuestro Señor:

- ¿Quieres que sembremos la huerta de media?

- Sí, la sembramos, ¿por qué no la vamos a sembrar?

Pues la labraron, los gastos a medias, el diablo y Dios. Entonces lo primero que hicieron fue hacerlo bien, le echaron tierra, le echaron estiércol, le echaron abono y entonces fueron y sembraron patatas. Como echaron es tiércol y basura... ¡unas plantas hermosísimas!

Y dijo Dios así... porque el diablo quería engañar a Dios, pero a Dios no se le escapa na, lo oye to, sabe más que nadie y lo ve to, ¡lo que le digo yo a mi niño!... Dice Dios:

-Bueno, vamos a ver, ¿tú qué quieres mejor lo de abajo o lo de arriba? Yo no quiero que digas después que luego te engaño - dijo Dios pa el diablo.

— ¡No!, no me engañas tú a mí, no — dijo el Diablo — ¡yo quiero lo de arriba!, ¡qué voy a querer lo de abajo!

Fue el diablo, cortó toas las ramas, to, pa el invierno. Dios fue, arrancó las patatas. Y el diablo comía las ramas secas, y Dios se comió las patatas. Bueno, eso fue lo de la patata.

Al otro año, en el barbecho, donde sembraban, sembraron trigo... ¡Un trigo de esta altura, unas espigas...! ¡Qué trigo, qué hermoso, más bueno! Dice:

-Bueno, te doy a escoger...

- ¡No, el año pasao me engañaste!

-No, te engañaste tú, yo te di a escoger. ¡Vamos a ver este año!, ¿qué quieres mejor, lo de arriba o lo de abajo?

—iAh!, ipillo! El año pasao me engañaste, pero este ya no me engañas. Este año yo quiero lo de abajo, lo de arriba lo coges tú.

De modo que también fue engañao, porque la espiga tiene el trigo y debajo lo que tenía eran las raíces podrías, que no servían pa na. Y el diablo siempre perdió, por eso yo veo que Dios sabe más que nadie. Y nunca pudo engañarle, Dios.

Una versión realmente sensacional del cuento folclórico conocido como $\mathrm{El}$ reparto de la cosecha, que tiene el número 1030 (Crop Division between Man and Ogre) en el catálogo internacional de cuentos de Aarne-Thompson-Uther. Porque resulta que otro de los méritos que atesora este libro es el de que incorpora en sus páginas, entreverados en los testimonios de sus narradores, un arsenal de cuentos, canciones, plegarias, paremias, etc. etc, etc. que lo convierten, por añadidura, en una de las grandes compilaciones que tenemos de literatura oral en nuestra lengua. 
Resta hacer una última y quizás impertinente reflexión: ¿qué se hizo de las grabaciones sonoras en que quedó recogido todo este inmenso coro de voces? ¿Podremos escucharlas alguna vez? ¿La transcripción de los testimonios no es un modo, en cierta medida, de empobrecer o de esquematizar la muestra, que nació con una fundamental dimensión oral, como un acto conversacional? La entonación, las pausas, los énfasis que se pierden en el momento del paso de lo oral a lo escrito, ¿no eran estrategias constitutivas y radicalmente significativas del discurso?

Las puertas que a la investigación de hoy abre este libro cuya originalidad queda realzada por el hecho de que fuera mayormente compuesto en los años 1983 y 1984 deben de ser franqueadas con todas esas cuestiones y preguntas, y con algunas más, en la cabeza. Las tecnologías audiviosuales actuales, con sus posibilidades de registro y sus programas casi automáticos de transcripción, es seguro que hubieran facilitado muchísimas de las labores serviles a las que habrá obligado la confección de un volumen tan extenso y complejo como es este. Pero además los documentos audiovisuales son, siempre y de manera innegable, superiores a los documentos escritos en el caudal y el refinamiento de la información y de la expresión que transmiten. Y si contásemos con registros sonoros o fílmicos de aquellas gentes, de sus testimonios, de sus paisajes, el valor que tendría este libro quedaría muy multiplicado.

Entre el año 1983 en que inició su andadura este libro y el 2016 en que la concluyó se ha interpuesto algo más que un cambio de siglo: ha habido también un cambio radical en las tecnologías y modos del registro, transmisión y recepción de la memoria. También, en consecuencia, en su interpretación. El que esta compilación de Imágenes y sentimientos en el cristianismo popular. Viejos testimonios de fieles extremeños haya podido dar ese salto y aterrizar en el siglo XXI como una propuesta llena de atrevimiento y novedad es, seguramente, el elogio más insólito que se puede hacer de él.

José Manuel PEDRosA

(Universidad de Alcalá)

$$
\text { i }
$$

